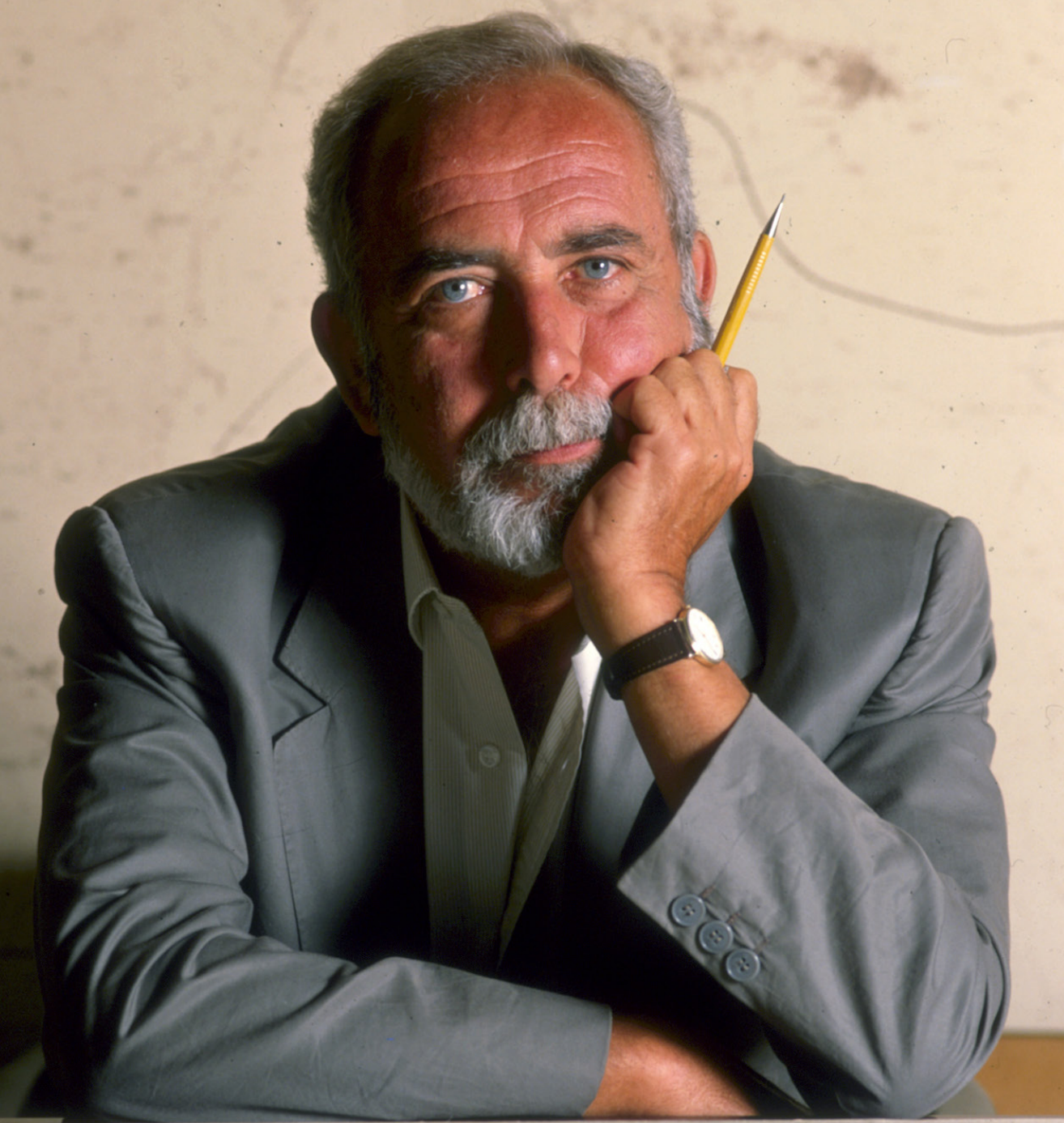

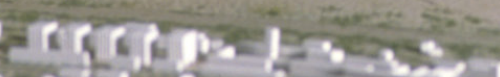

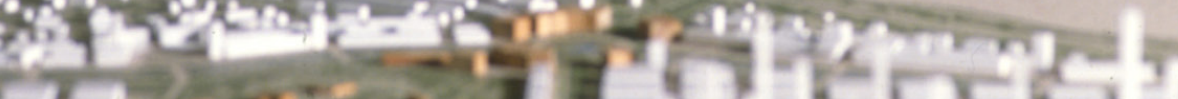

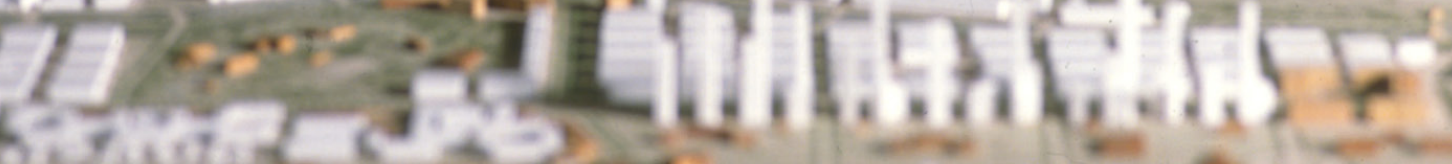

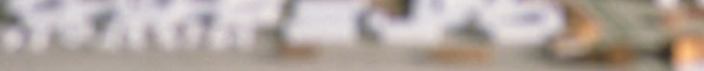




\section{ARQUITECTOS Y URBANISTAS, ¿PARA QUÉ?}

Un grupo de alumnos de arquitectura, mediada ya la carrera, me plantea la siguiente cuestión: arquitectos y urbanistas ¿para qué? Intento una respuesta inmediata, pero me doy cuenta de la frivolidad y les pido un par de días antes de mandarles un email con mis reflexiones, más que mis contestaciones. La pregunta de los alumnos abre, para matizarla mínimamente, otro interrogante: ¿de qué arquitectura hablamos o que entendemos por arquitectura? Y, de forma semejante: ¿qué entendemos por urbanismo?

Una primera condición que me autoimpongo es dejar fuera cualquier tentación de ser el experto por encima de mis interpelantes, de ser dueño de la verdad. Vienen en mi apoyo algunas citas ilustres. Lessing prefiere la "búsqueda de la verdad" a la "posesión de la verdad". Nietzsche afirma que "las convicciones fundamentalistas se convierten en prisiones". Pascal grita " $\mathrm{iNada}$ es cierto!”. Y nuestro poeta Ángel Valente sentencia “¡Murió, es decir, supo la verdad!". Casi nunca hay una sola respuesta cuando nos planteamos preguntas sobre temas complejos referidos a la forma de vivir de los hombres y las formas en que se expresa a través del arte.

Arquitectos, ¿para qué?, me obliga a una aproximación, muy simplificada, de qué es un arquitecto, pudiendo definirlo remitiéndome a su profesión, "cuyo principal contenido es dar forma física las demandas y anhelos de cada individuo y de la sociedad en su conjunto" (Ricard Pié) o, como dice Antón Capitel, "la conversión en arte de una necesidad humana, la construcción de cobijo", la casa y la ciudad, función y símbolo a la vez.

Los arquitectos serán necesarios mientras el hombre necesite cuatro paredes y un techo para resguardarse de las fuerzas de la naturaleza, para recrearse en su intimidad y silencio, para reunirse y debatir, para cantar solo o en coro, para rezar... será necesario el arquitecto como mediador entre la demanda de la sociedad o del individuo y el constructor, ya que en muy raras ocasiones (quizá solo en las sociedades primitivas) el hombre puede construirse su propio alojamiento. Y tengamos presente que la casa, la iglesia, el parlamento o el teatro, no solo es un recinto protegido, sino un símbolo, un icono visible y reconocible ante el conjunto de la sociedad. Requiere, por tanto, pericia técnica y artisticidad.

¿Y los urbanistas? Mientras los hombres sigan queriendo vivir juntos en un espacio complejo que llamamos ciudad, serán necesarios "los urbanistas", 
con la titulación que sea. Profesionales capaces de dar forma al espacio colectivo y multifuncional. Pero la ciudad no es solo un espacio funcional en el que se desarrolla de la forma más efectiva y satisfactoria posible la actividad de los ciudadanos, sino que es un espacio arquitectónico, es decir, un espacio con una forma organizada que quiere ser bello.

Oriol Bohigas escribe: "La forma de la ciudad es un elemento fundamental para su buen funcionamiento y para su adecuada interpretación”. Para ello la primera condición es "proyectar ordenadamente la forma del espacio público".

Y ahora soy yo el que me pregunto ¿cómo se aprende a ser arquitecto? ¡cómo se aprende la arquitectura? La arquitectura es lo que han hecho los buenos arquitectos a lo largo de la historia. Lo que han hecho Brunelleschi, Miguel Ángel, Palladio, Juan de Herrera... y más cercanos Le Corbusier, Mies, Aalto, Siza, Piano, Moneo o, más aún, Murcutt o Zumthor. La arquitectura son los buenos edificios construidos con rigor técnico y belleza. Mies renegaba cuando lo llamaban arquitecto, el se definía como constructor con arte. Por eso es difícil, casi imposible, definir y aprender arquitectura desde conceptos filosóficos o reflexiones teóricas sobre "el arte": porque la arquitectura es materia, materia bien manejada, bien "aparejada", que se transforma en forma útil y bella para el hombre. Por eso la arquitectura solo se aprende de la "arquitectura" construida, vista y tocada por quien quiera aprender a ser arquitecto. Es del esfuerzo por entender los buenos edificios, de someterlos a disección, de copiarlos, como se aprende arquitectura. Para este difícil ejercicio necesitaremos los ojos y las manos, pero también la inteligencia debidamente cultivada, es decir, la "cultura”. Leer filosofía, poesía, historia, sociología, religión... para agudizar nuestros sentidos con el aguijón de nuestra mente.

¿Y el urbanismo? Más o menos lo mismo. Conocer las ciudades, empezando por la tuya propia. Conocerlas desde el aire (Google Earth) y desde el pavimento. Medir sus calles con nuestros pasos. Calcular las distancias con nuestros ojos y comprobarlas después con el metro o el teodolito. Ver el comportamiento de la gente paseando, a pie o en coche, sentada en un banco, celebrando una fiesta colectiva o reivindicando sus derechos en una airada manifestación. Luis Fernández Galiano escribe: "tanto los espacios urbanos como los grandes ámbitos de los edificios públicos solo adquieren sentido cuando se convierten en escenario y marco de la vida social, y es la coreografía de la celebración o la protesta, del espectáculo o el duelo, lo que otorga vida y significado a las fábricas inertes de la arquitectura”. Y Manuel de Solà-Morales, en un corto escrito denominado Between de bars (Balada, de Elliot Smith, finales de los 90), recomienda a un amigo que para conocer Barcelona recorra una lista de doce bares que, siendo interesantes en su interior y lo que sirven, cobran significado "por el lugar en que están situados y por el uso que establecen entre el interior y el exterior", para concluir "Entre los bares, la ciudad. Lo que hay entre los bares, eso es la ciudad. ¿Me has entendido?”. 
Y dibujar con el lápiz una y otra vez, los trazados, los alzados, la topografía de la ciudad. Dibujar, dibujar y dibujar, hasta que la ciudad se nos quede en la memoria de nuestros dedos, para luego poder proyectarla usando a la vez el centímetro y el kilómetro. Por trozos, desde lo pequeño a lo grande. Invirtiendo el axioma de los racionalistas heroicos, aquí la forma es lo que posibilita la función.

¿Y los planes de los que tanto nos hablan en la escuela? Superado su carácter jurídico-administrativo, necesario para una convivencia civilizada y el control de los agentes públicos y privados en la construcción de la ciudad, los planes que son necesarios son aquellos que son capaces de proyectar la ciudad, "es decir, a poner en relación conceptos y formas, ideas y materiales", palabras de Solà-Morales, que afirma: "Hay que hacer planes. ¡Claro que hay que hacer planes! Planes, proyectos, metaproyectos, avances, esquemas, ideas, visiones, estrategias de cualquier naturaleza y escala. Sobre todo, hoy, de alcance territorial, de ingeniería y geografía urbanísticas, de economía y biología urbanísticas. Redactados por quien sepa hacerlos. Urbanísticos por su contenido y alcance y no por su perímetro".

¿Hasta cuando los arquitectos? Los arquitectos serán demandados por la sociedad y, por tanto, seguirán existiendo y siendo necesarios, si su trabajo está dirigido a resolver, a garantizar una satisfactoria "habitabilidad" para los hombres, para los ciudadanos. Y no se atrincheren en su función de diseñadores de iconos brillantes, novedosos y caros, al servicio del negocio inmobiliario o de la exhibición de políticos e instituciones. O, en sentido contrario, no se reducen a vulgares funcionarios que con su firma legitiman o, al menos, legalizan los horrores que inundan nuestras ciudades, costas y montañas.

Invocación final. Para que la arquitectura y el urbanismo sigan siendo oficios nobles y útiles es necesario un rearme moral, ideológico, de los arquitectos y urbanistas, "amenazados como estamos por dos carcomas éticas, igualmente letales: el pesimismo y el cinismo” (Solà-Morales). 